\title{
Epidemiologic characteristics of health care-associated outbreaks and lessons learned from multiple outbreak investigations with a focus on the usefulness of routine molecular analysis
}

\author{
Hajime Kanamori MD, PhD, MPH a,b,*, David J. Weber MD, MPH a,b, \\ Maria F. Gergen MT (ASCP) a, Lauren M. DiBiase MS a,b, \\ Emily E. Sickbert-Bennett PhD, MS a,b, William A. Rutala PhD, MPH a,b \\ a Hospital Epidemiology, University of North Carolina Health Care, Chapel Hill, NC \\ ${ }^{\mathrm{b}}$ Division of Infectious Diseases, University of North Carolina, Chapel Hill, NC
}

\section{Key Words:}

Outbreak

Health care-associated infection

Pulsed-field gel electrophoresis

Nosocomial

\begin{abstract}
Background: Single outbreaks have often been reported in health care settings, but the frequency of outbreaks at a hospital over time has not been described. We examined epidemiologic features of all health care-associated outbreak investigations at an academic hospital during a 5-year period.

Methods: Health care-associated outbreak investigations at an academic hospital (2012-2016) were retrospectively reviewed through data on comprehensive hospital-wide surveillance and pulsed-field gel electrophoresis (PFGE) analysis.

Results: Fifty-one health care-associated outbreaks (annual range, 8-15), including 26 (51\%) outbreaks in intensive care units (ICUs), and 263 infected-colonized patients involved in these outbreaks were identified. The frequency of pathogens varied by affected location, specifically multidrug-resistant organisms (20/26 outbreaks, $77 \%$ in ICUs vs $2 / 25$ outbreaks, $8 \%$ in non-ICUs; $P<.0001$ ) and gastroenteritis because of Clostridium difficile, norovirus, or adenovirus (1/26 outbreaks, 4\% in ICUs vs $17 / 25$ outbreaks, $68 \%$ in non-ICUs; $P<.0001)$. Outbreaks occurred in approximately one-third of all units $(37 \%)$ with some repeated instances of the same pathogens. Of 16 outbreaks caused by a bacterial pathogen evaluated by PFGE, 12 (75\%) included some indistinguishable strains, suggesting person-to-person transmission or a common source.

Conclusions: This study demonstrated epidemiologic characteristics of multiple outbreaks between ICUs and non-ICUs and the value of molecular typing in understanding the epidemiology of health careassociated outbreaks.
\end{abstract}

Multiple pathogens, including viruses, bacteria, mycobacteria, and fungi, and multiple reservoirs-sources, including health care personnel, patients, visitors, surface environment, medical equipment, air, and water, have been involved in health care-associated outbreaks. ${ }^{1-5}$ Health care-associated outbreaks not only may affect patients' morbidity and mortality but also may have severe repercussions in health care operations (eg, ward closure) with the need for time-consuming and potentially expensive interventions. ${ }^{4}$

\footnotetext{
* Address correspondence to Hajime Kanamori, MD, PhD, MPH, Department of Infection Control and Laboratory Diagnostics, Internal Medicine, Tohoku University Graduate School of Medicine, 1-1 Seiryo-machi, Aobaku, Sendai 980-8574, Japan.

E-mail addresses: kanamori@med.tohoku.ac.jp, kanamori@med.unc.edu (H. Kanamori)

Conflicts of interest: None to report.
}

Single outbreaks caused by a specific pathogen(s) and a source or reservoir have often been reported in hospitals. However, the burden of outbreaks on a hospital over time is still poorly understood. Although there are many publications of outbreak investigations in a single hospital, ${ }^{4,6}$ they are likely to be substantially affected by publication bias with larger outbreaks, and those caused by novel reservoirs or routes of transmission, more likely to be published. In addition, concern about health care facility reputation and the risk of legal consequences may interfere with data sharing and obscure the real impact of outbreaks on daily practice in a health care facility. ${ }^{6,7}$ To our knowledge, there are no published reports of multiple outbreaks caused by diverse pathogens at an academic medical center and the value of routine molecular typing of pathogens associated with an outbreak over time. 
In this study, we assessed all health care-associated outbreak investigations based on routine practice, examined the value of pulsed-field gel electrophoresis (PFGE) of pathogens involved in outbreaks, and reviewed lessons learned from these multiple investigations at an academic hospital during a 5-year period.

\section{METHODS}

This analysis was conducted at an 853-bed tertiary care academic facility with 41 inpatient nursing units. Health careassociated outbreak investigations at our hospital from 20122016 were retrospectively reviewed through an institutional health care-associated infection (HAI) database and monthly reports to the hospital infection control committee. Using a laboratorybased pathogen detection system to conduct comprehensive hospitalwide surveillance, outbreak investigations were triggered by an increase in number of infections or pathogens above baseline rate in a unit during a specified period of time; an investigation may also have been triggered by a single case of a rare and epidemiologically important pathogen. ${ }^{4}$ In this study, the number of potential health care-associated outbreaks was counted as the number of the corresponding outbreak investigations, including one with only a single case (ie, Legionella). Additionally, a health careassociated outbreak identified by molecular typing was defined as (1) cases that overlapped time and space and (2) at least 2 isolates linked by PFGE. Contact tracing associated with exposure investigations of a single patient (eg, varicella, tuberculosis) with a communicable disease were excluded from analysis. Variables in the outbreak investigations included year, duration of outbreak, location, pathogen, presence or absence of HAI, type of specific HAI, number of patients infected-colonized, number of health care personnel involved, presence or absence of PFGE with number of isolates and number of different patterns when PFGE was performed, and brief summary of infection control measures and interventions.

Comprehensive hospital-wide surveillance for all HAIs, including all sites defined by the Centers for Disease Control and Prevention, was conducted through a chart review of each patient in accordance with the Centers for Disease Control and Prevention criteria. ${ }^{8}$ Our HAI surveillance included components of laboratory reports of positive culture results, results of serologic testing or molecular-based diagnostic tests, clinical reports of infections, morbidity and mortality conferences, and autopsies. HAIs are classified into one of the following 5 major infections with 14 specific infection sites: bloodstream infections, urinary tract infections, respiratory tract infections (pneumonia and lower respiratory tract infections), surgical site infections, and other type of HAIs (gastrointestinal infections; eye, ear, nose, throat, or mouth infections; skin and softtissue infections; cardiovascular system infections; bone and joint infections; central nervous system infections; reproductive tract infections; and systemic infections). All surveillance data of HAIs and outbreak investigations during the study period were entered into an electronic database. This study was approved by the Institutional Review Board of University of North Carolina at Chapel Hill.

PFGE was performed for selected bacterial pathogens based on likelihood of an epidemiologic link (eg, $>3$ pathogens overlapping in time and location). We reviewed all PFGE analyses performed during the study period. Environmental sampling of the hospital and hand sampling of health care personnel depended on ongoing situation of an outbreak or type of pathogen.

Statistical analyses were performed by 2-tailed Fisher test using JMP 11 (Statistical Analysis System, Cary, NC); $P \leq .05$ was considered to be statistically significant.

\section{RESULTS}

Fifty-one health care-associated outbreaks (annual range, 8-15), including 26 (51\%) outbreaks in ICUs and 25 (49\%) outbreaks in nonICUs, were identified during the study period. The annual number of outbreaks was almost constant except for 2015 with an increase in gastroenteritis, whereas epidemiologic features (eg, pathogen type) in these outbreaks substantially differed by year (Fig 1). Outbreaks occurred in 15 units (36.6\% of all 41 inpatient units). Of the 26 outbreaks in ICUs, 12 (46.2\%) and 7 (26.9\%) occurred in the burn ICU and the neonatal ICU, respectively. Of the 25 outbreaks in non-ICUs, 6 (24\%) occurred in the bone marrow transplant unit. An outbreak of Stenotrophomonas maltophilia involved multiple nursing units. Overall, 30 (58.8\%) outbreaks were terminated within 1 month, whereas 4 (7.8\%) continued for $>6$ months (ie, 1 methicillin-resistant Staphylococcus aureus [MRSA] outbreak in the neonatal ICU, 1 carbapenem-resistant Enterobacteriaceae [CRE] outbreak in the burn ICU, 2 multidrug-resistant Pseudomonas outbreaks in the burn ICU). The frequency of outbreaks sustained over 2 months was significantly higher in ICUs than in non-ICUs (Table 1), and the burn ICU accounted for 52.6\% (10/19) of these prolonged outbreaks in ICUs.

The frequency of pathogens varied greatly by affected location, specifically multidrug-resistant organisms (MDROs) in ICUs (MRSA, CRE, and multidrug-resistant Pseudomonas aeruginosa) and gastroenteritis in non-ICUs (Clostridium difficile, norovirus, and adenovirus) (Fig 2, Table 1). Of 34 bacterial outbreaks, an MDRO (22 outbreaks, $64.7 \%$ ) was the most frequent, followed by $C$ difficile ( 7 outbreaks, 20.6\%). Eleven viral outbreaks included 7 (63.6\%) norovirus gastroenteritis, 2 adenovirus gastroenteritis, 1 enterovirus meningitis, and 1 influenza respiratory infection, whereas $75 \%$ of all fungal outbreaks (3/4) were caused by Rhizopus spp. A pseudooutbreak of Ralstonia insidiosa via a contaminated sonicator occurred in a laboratory during the study period. The frequency of outbreaks of repeated pathogens at the same location was 63\%, and outbreaks in ICUs significantly tended to reoccur more commonly than those in non-ICUs (Table 1).

Of the 51 outbreaks, 47 (92.2\%) resulted in HAIs. Gastroenteritis $(\mathrm{n}=18,35.3 \%)$ was the most common type of infection, followed by pneumonia ( $n=9,17.6 \%)$, bloodstream infection $(n=8,15.7 \%)$, and skin and soft-tissue infection $(n=8,15.7 \%)$, whereas there were no HAIs identified in 4 (7.8\%) investigations. The type of HAIs differed significantly within or outside an ICU (Table 1). Overall, 263 infected-colonized patients (median, 4; range, 1-20) were involved in health care-associated outbreaks. There was no statistical

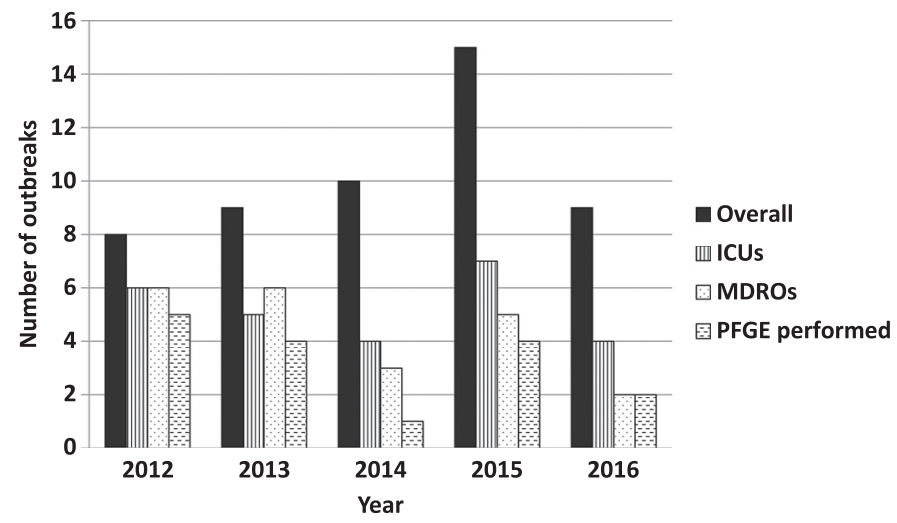

Fig 1. Annual trends in health care-associated outbreak investigations at an academic hospital, 2012-2016. ICU, intensive care unit; MDRO, multidrug-resistant organism; PFGE, pulsed-field gel electrophoresis. 
Table 1

Epidemiologic characteristics of health care-associated outbreaks at an academic hospital, 2012-2016

\begin{tabular}{|c|c|c|c|c|c|c|c|}
\hline \multirow[b]{2}{*}{ Characteristic } & \multicolumn{2}{|c|}{ Overall $(\mathrm{N}=51)$} & \multicolumn{2}{|c|}{ ICUs $(n=26)$} & \multicolumn{2}{|c|}{ Non-ICUs $(\mathrm{n}=25)$} & \multirow{2}{*}{$\frac{\text { ICUs vs non-ICUs }}{P \text { value* }^{*}}$} \\
\hline & $\mathrm{n}$ & $\%$ & $\mathrm{n}$ & $\%$ & $\mathrm{n}$ & $\%$ & \\
\hline \multicolumn{8}{|l|}{ Duration } \\
\hline$>2 \mathrm{mo}$ & 21 & 41 & 19 & 73 & 2 & 8 & $<.0001$ \\
\hline \multicolumn{8}{|l|}{ Pathogen } \\
\hline MDRO & 22 & 43 & 20 & 77 & 2 & 8 & $<.0001$ \\
\hline Clostridium difficile & 7 & 14 & 0 & 0 & 7 & 28 & .0042 \\
\hline Norovirus & 7 & 14 & 0 & 0 & 7 & 28 & .0042 \\
\hline Repeated pathogen at same location & 32 & 63 & 23 & 88 & 9 & 36 & .0001 \\
\hline \multicolumn{8}{|l|}{ Infection type } \\
\hline Any HAI & 47 & 92 & 23 & 88 & 24 & 96 & \\
\hline Pneumonia & 9 & 18 & 8 & 31 & 1 & 4 & .0238 \\
\hline Lower respiratory tract infection & 6 & 12 & 6 & 23 & 0 & 0 & .0226 \\
\hline Bloodstream infection & 8 & 16 & 7 & 27 & 1 & 4 & .0496 \\
\hline Urinary tract infection & 3 & 6 & 2 & 8 & 1 & 4 & \\
\hline Surgical site infection & 3 & 6 & 2 & 8 & 1 & 4 & \\
\hline Gastroenteritis & 18 & 35 & 1 & 4 & 17 & 68 & $<.0001$ \\
\hline Skin and soft-tissue infection & 8 & 16 & 7 & 27 & 1 & 4 & .0496 \\
\hline \multicolumn{8}{|l|}{ Population } \\
\hline$>4$ patients involved in an outbreak & 29 & 57 & 16 & 62 & 13 & 52 & \\
\hline$>2$ staff involved in an outbreak & 9 & 18 & 1 & 4 & 8 & 32 & .0109 \\
\hline \multicolumn{8}{|l|}{ Genotyping } \\
\hline PFGE performed & 16 & 31 & 14 & 54 & 2 & 8 & .0006 \\
\hline \multicolumn{8}{|l|}{ Control measure } \\
\hline Isolation or cohorting & 37 & 73 & 18 & 69 & 19 & 76 & \\
\hline Enhanced hand hygiene & 20 & 39 & 12 & 46 & 8 & 32 & \\
\hline Enhanced cleaning-disinfection & 29 & 57 & 11 & 42 & 18 & 72 & .0483 \\
\hline Modification of care or equipment & 21 & 41 & 13 & 50 & 8 & 32 & \\
\hline Patient screening or surveillance & 14 & 27 & 13 & 50 & 1 & 4 & .0003 \\
\hline Closure of affected location & 7 & 14 & 0 & 0 & 7 & 28 & .0042 \\
\hline Restriction of work & 7 & 14 & 0 & 0 & 7 & 28 & .0042 \\
\hline
\end{tabular}

$H A I$, health care-associated infection; $I C U$, intensive care unit; $M D R O$, multidrug-resistant organism; PFGE, pulsed-field gel electrophoresis.

${ }^{*} P$ values are shown only when $P \leq .05$.

difference in the number of patients per outbreak between ICUs and non-ICUs, but health care personnel were significantly more likely to be involved in outbreaks in non-ICU epidemics (Table 1).

Of 16 outbreaks caused by a bacterial pathogen (total of 99 bacteria isolates; median, 4.5; range, 2-20) evaluated by PFGE, including 13 (81.3\%) outbreaks caused by an MDRO, 12 (outbreaks demonstrated by PFGE, 75\%) included some indistinguishable strains, suggesting person-to-person transmission or a common source, whereas 4 (outbreaks differed by PFGE, 25\%) demonstrated only unique strains (Table 2). Of 12 PFGE clonal outbreaks, 11 (91.7\%) were implicated in HAIs, whereas there were no HAIs identified during a vancomycin-resistant enterococci outbreak in the 2013 bone marrow transplant unit. All 4 PFGE different outbreaks caused HAIs. PFGE were more frequently performed in ICU outbreaks than in nonICU outbreaks (Table 1).

Hand sampling from health care personnel was conducted in a prolonged investigation of MRSA in a neonatal ICU which revealed that health care personnel hands at times carried the outbreak strain, suggesting deficiencies in hand hygiene compliance. Environmental sampling was performed in 3 investigations during the 5-year period. Outbreak 1 (with air sampling) involved invasive cutaneous Rhizopus infections among immunocompromised patients in the ICU because of contaminated laundry carts. ${ }^{9}$ Outbreak 2 (with water sampling) involved susceptible $P$ aeruginosa surgical site infections in a neurosurgical ICU; all 4 patients had $P$ aeruginosa strains indistinguishable with those isolated from a sink aerator within the ICU. Outbreak 3 (with water sampling) involved nontuberculosis mycobacteria skin infection at a dermatology clinic; Mycobacterium mucogenicum was isolated from a water sample, but multiple different nontuberculous mycobacteria species (2 cases of Mycobacterium chelonae and 2 cases of Mycobacterium abscessus) were involved in the outbreak, and our investigation did not reveal a possible environmental source.
Infection control measures varied for each outbreak, and multiple measures were often implemented simultaneously. The most frequent enhanced infection control measure implemented was isolation or cohorting $(n=37,72.5 \%)$, followed by enhanced cleaningdisinfection (eg, disinfection with bleach) $(\mathrm{n}=29,56.9 \%)$, modification of care or equipment ( $n=21,41.2 \%)$, and enhanced hand hygiene education ( $\mathrm{n}=20,39.2 \%$ ) (Table 1$)$. Importantly, 7 (13.7\%) outbreak investigations led to closure of the affected location (norovirus: $n=4$, other gastroenteritis: $n=1$, influenza: $n=1$, and vancomycin-resistant enterococci: $n=1$ ) and restriction of health care personnel working off the affected unit (norovirus: $n=6$ and $C$ difficile: $\mathrm{n}=1$ ). Besides enhanced cleaning-disinfection, a ultraviolet-C (UV-C) device was used for terminal disinfection in 3 outbreaks (5.9\%) because of vancomycin-resistant enterococci, $C$ difficile, or norovirus. Affected locations in non-ICUs were more frequently closed to new admissions as part of enhanced infection prevention efforts because patients in non-ICUs were commonly mobile and pathogens causing these outbreaks (eg, norovirus, $C$ difficile, influenza) tended to be spread from person-to-person.

\section{DISCUSSION}

This study characterized the epidemiology of multiple outbreaks over time at a single academic hospital. We have previously described at our hospital substantial reductions in overall HAIs, especially HAIs in ICUs, through comprehensive hospital-wide surveillance (2001-2012). ${ }^{10}$ On the other hand, there were still substantial numbers of outbreak investigations during the study period (2012-2016); however, the data do not exist to assess how this compares with other similar facilities. MDROs were the most frequent pathogen in health care-associated outbreaks in this study, and MRSA accounted for half of the MDRO outbreaks. Half of all outbreaks occurred in ICUs, most commonly in the burn ICU and 

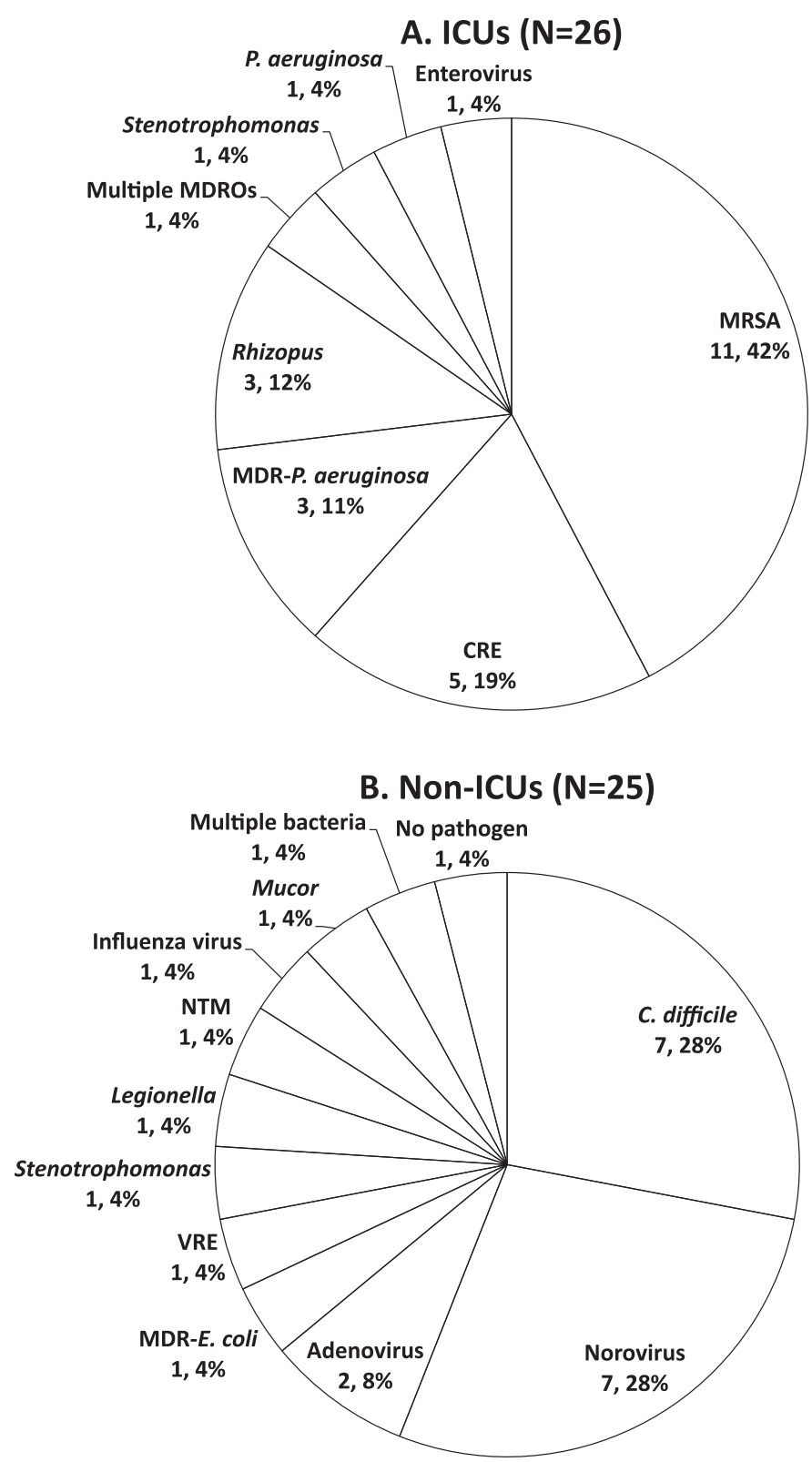

Fig 2. Frequency of pathogens involved in health care-associated outbreak investigations in ICUs (A) and non-ICUs (B) at an academic hospital, 2012-2016. CRE, carbapenem-resistant Enterobacteriaceae; ICU, intensive care unit; $M D R$, multidrug resistant; MDRO, multidrug-resistant organism; MRSA, methicillin-resistant Staphylococcus aureus; No pathogen, an investigation for patients with gastrointestinal symptom has not identified a causative pathogen; NTM, nontuberculous mycobacteria; VRE, vancomycin-resistant enterococci.

neonatal ICU. Importantly, outbreaks occurred in approximately onethird of all units with some repeated instances of the same pathogens, therefore demonstrating the importance of facilitywide comprehensive surveillance for HAIs. Because we perform hospital-wide surveillance, we do not think the distribution of our outbreaks was biased by selective surveillance. We also found significant differences in health care-associated outbreaks between ICUs and non-ICUs. Assessing epidemiologic trends of outbreaks over time can help health care facilities direct surveillance and prevention strategies against health care-associated outbreaks toward these specific types of HAIs, pathogens, and affected locations.

The most common outbreaks in this study were MRSA in the neonatal ICU $(n=6)$, MDROs in the burn ICU $(n=12)$, and norovirus in
non-ICU units ( $\mathrm{n}=7$ ). Neonates have immature immune systems and are vulnerable to HAIs, and neonatal ICUs are a high-risk setting for health care-associated outbreaks.,11 Severe patients with burn injury are associated with outbreaks of MDRO that can lead to morbidity and mortality in this population and challenges for infection prevention and control. ${ }^{12-14}$ In both neonates and burn patients, use of multiple invasive devices and contact with multiple health care personnel are common. Norovirus is a leading cause of gastroenteritis in settings where rotavirus immunization is implemented, and its outbreaks are often associated with genogroup II type 4 strains, posing a major burden in health care facilities. ${ }^{4,15,16}$

$C$ difficile was also an important pathogen associated with outbreaks, especially in a bone marrow transplant unit, and our previous study showed that $C$ difficile infection has been our most common health care-associated pathogen in our facility..$^{10}$ Leukemia patients were at a higher risk of $C$ difficile infection and have been reported to be associated with increased mortality in their cases of $C$ difficile infection. ${ }^{17}$ Transmission of $C$ difficile infection was thought to be predominant in health care settings, and infection prevention efforts were prioritized on symptomatic patients, and the substantial portion of $C$ difficile isolates from symptomatic patients was genetically distinguishable by whole-genome sequencing (WGS), suggesting diverse sources of $C$ difficile, including asymptomatic patients and environment. ${ }^{18}$

PFGE has been widely used as the gold standard for strain typing and has provided useful information in confirming or refuting epidemiologic links for MDRO outbreak investigations in our study (Table 2). Recognizing outbreak status demonstrated by PFGE can lead to reeducation of health care personnel to enhance infection control measures such as hand hygiene, environmental cleaningdisinfection, and disinfection of shared medical equipment. It may also lead to consideration of a common source or reservoir. Moreover, when initial PFGE results indicate that clinical isolates are indistinguishable, additional sampling (eg, environmental or hand sampling) can be considered.

PFGE has advantages and disadvantages. PFGE is advantageous to multiple cases by certain pathogen (eg, MDROs), prolonged outbreaks, and outbreaks via environmental source. Disadvantages of PFGE include that the method is labor-intensive, time-consuming, and moderately technically demanding, and PFGE can have discrepancy in reproducibility and interpretation among personnel and facilities. ${ }^{19}$ An additional research investigation in our hospital using WGS revealed that CRE outbreaks at the burn ICU, which seemed epidemiologically unlinked, were actually genetically linked over a prolonged period and were driven by multiple mechanisms of resistance transmission among same or different species, affirming other studies that WGS has become a better method for advanced molecular typing in outbreak investigations compared with PFGE. ${ }^{13,14,19,20}$

In a few of our investigations, environmental sampling contributed to identifying a potential reservoir or source of outbreaks. Environmental sampling can be considered in some outbreak investigations but is not routinely recommended, and standard environmental sampling method and interpretation of microbial results is not well established. ${ }^{21}$ In our investigations, when outbreaks caused by a dominant strain of a certain pathogen (eg, gramnegative bacteria) among several patients continued for a prolonged time or were considered to be typical of a point source outbreak related to the hospital environment and medical equipment, environmental sampling was performed. In a prolonged outbreak (eg, MRSA), hand sampling of health care personnel was performed to emphasize the importance of hand hygiene.

Most outbreaks in this study were terminated rapidly by enhanced control measures. Unit closure and work restriction severely affect operation of health care facilities, and commonly norovirus 
Table 2

Summary of health care-associated outbreaks evaluated by PFGE at an academic hospital, 2012-2016

\begin{tabular}{|c|c|c|c|c|c|c|c|c|c|}
\hline Location & $\begin{array}{l}\text { Duration } \\
\text { (mo) }\end{array}$ & Pathogen & HAI & $\begin{array}{l}\text { No. of } \\
\text { patients } \\
\text { involved }\end{array}$ & $\begin{array}{l}\text { No. of } \\
\text { staff } \\
\text { involved }\end{array}$ & $\begin{array}{l}\text { No. of } \\
\text { isolates } \\
\text { on PFGE }\end{array}$ & $\begin{array}{l}\text { No. of different } \\
\text { PFGE patterns }\end{array}$ & $\begin{array}{l}\text { Environmental or } \\
\text { hand sampling }\end{array}$ & Control measure in addition to standard practice \\
\hline Burn ICU & 12 & MDR P. aeruginosa & VAP, LRI & 20 & 0 & 10 & $3^{*}$ & No & $\begin{array}{l}\text { Isolation or cohorting, enhanced hand hygiene, } \\
\text { enhanced cleaning-disinfection, modification of care } \\
\text { or equipment, patient screening or surveillance }\end{array}$ \\
\hline Neonatal ICU & 4 & MRSA & SST & 5 & 0 & 7 & $2^{*}$ & No & $\begin{array}{l}\text { Isolation or cohorting, patient screening or } \\
\text { surveillance, enhanced hand hygiene, enhanced } \\
\text { cleaning-disinfection }\end{array}$ \\
\hline $\begin{array}{l}\text { BMTU, unit A, } \\
\text { unit B }\end{array}$ & $\leq 1$ & $\begin{array}{l}\text { Stenotrophomonas } \\
\text { maltophilia }\end{array}$ & CLABSI & 4 & 0 & 4 & 4 & No & Not required \\
\hline Neurosurgical ICU & 2 & MRSA & RTI & 6 & 0 & 4 & $2^{*}$ & No & $\begin{array}{l}\text { Enhanced hand hygiene, modification of care or } \\
\text { equipment }\end{array}$ \\
\hline Neonatal ICU & 2 & MRSA & SSI, BSI, conjunctivitis & 7 & 0 & 2 & 2 & No & $\begin{array}{l}\text { Isolation or cohorting, patient screening or } \\
\text { surveillance, enhanced hand hygiene, enhanced } \\
\text { cleaning-disinfection }\end{array}$ \\
\hline BMTU & $\leq 1$ & VRE & No (colonization) & 8 & 0 & 8 & $5^{*}$ & No & $\begin{array}{l}\text { Closure of affected location, isolation or cohorting, } \\
\text { enhanced cleaning-disinfection, modification of care } \\
\text { or equipment, use of UV-C device }\end{array}$ \\
\hline Neonatal ICU & 11 & MRSA & SST, VAP, BSI & 12 & 29 & 20 & $4^{*}$ & Hand sampling & $\begin{array}{l}\text { Isolation or cohorting, patient screening or } \\
\text { surveillance, modification of care or equipment, } \\
\text { enhanced hand hygiene, enhanced cleaning- } \\
\text { disinfection }\end{array}$ \\
\hline Neurosurgical ICU & $\leq 1$ & MRSA & RTI & 5 & 0 & 5 & $3^{*}$ & No & $\begin{array}{l}\text { Isolation or cohorting, enhanced hand hygiene, } \\
\text { enhanced cleaning-disinfection }\end{array}$ \\
\hline Burn ICU & 3 & $\begin{array}{l}\text { CRE } \\
\text { (Enterobacter sp) }\end{array}$ & VAP, LRI & 4 & 0 & 4 & $1^{*}$ & No & $\begin{array}{l}\text { Enhanced hand hygiene, enhanced cleaning- } \\
\text { disinfection }\end{array}$ \\
\hline Burn ICU & $\leq 1$ & MRSA & LRI & 3 & 0 & 3 & 3 & No & Not required \\
\hline Burn ICU & 2 & MRSA & VAE, VAP, CLABSI & 4 & 0 & 4 & $3^{*}$ & No & $\begin{array}{l}\text { Isolation or cohorting, enhanced hand hygiene, } \\
\text { enhanced cleaning-disinfection }\end{array}$ \\
\hline Burn ICU & 4 & $\mathrm{MDROs}^{\dagger}$ & HAIs ${ }^{\ddagger}$ & 9 & 0 & 2 (MRSA) & 2 & No & $\begin{array}{l}\text { Enhanced hand hygiene, enhanced cleaning- } \\
\text { disinfection, isolation or cohorting, modification of } \\
\text { care or equipment }\end{array}$ \\
\hline Neonatal ICU & 3 & MRSA & CLABSI, BSI, GI & 12 & 0 & 8 & $4^{*}$ & No & $\begin{array}{l}\text { Patient screening or surveillance, isolation or } \\
\text { cohorting }\end{array}$ \\
\hline Medical ICU & 2 & S maltophilia & VAP & 7 & 0 & 4 & 3* & No & Enhanced hand hygiene \\
\hline Neurosurgical ICU & 3 & $\begin{array}{l}\text { Pseudomonas } \\
\text { aeruginosa } \\
\text { (susceptible) }\end{array}$ & SSI & 4 & 0 & 7 & $4^{*}$ & $\begin{array}{l}\text { Environmental } \\
\text { sampling with } \\
\text { water sampling }\end{array}$ & Modification of care or equipment \\
\hline Burn ICU & 3 & MRSA & Pneumonia, SST, UTI, BJ & 5 & 0 & 7 & $3^{*}$ & No & Isolation or cohorting, enhanced hand hygiene \\
\hline
\end{tabular}

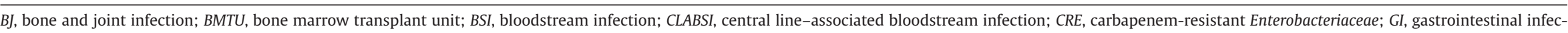

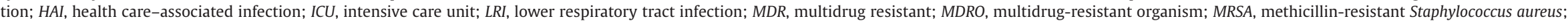

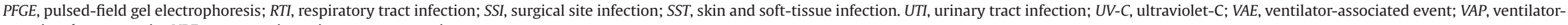
associated pneumonia; VRE, vancomycin-resistant enterococci.

*PFGE results include at least 2 linked isolates.

${ }^{\dagger}$ MDROs include MDR Enterobacter cloacae, MDR Proteus mirabilis, MRSA, CRE, MDR Acinetobacter, and MDR P aeruginosa.

‡HAIs include VAP and BSI with MRSA, and SST with MDR P aeruginosa, but no HAIs with Escherichia coli. 
outbreaks resulted in these extreme measures. ${ }^{22}$ In addition to enhanced environmental cleaning-disinfection, an ultraviolet- $C$ device was used in a few instances. Increasing experimental and clinical evidence for patient room disinfection using an ultraviolet-C device has demonstrated their efficacy against health care-associated pathogens. $^{23,24}$

One limitation is that our analysis was conducted at a single academic hospital and may not be generalizable to other health care facilities. There are no standard criteria for a specific number of cases to define a health care-associated outbreak and compare multiple outbreaks, and there are limited articles reporting in a standardized structure even in published outbreaks. ${ }^{6}$ Stone et al proposed the outbreak reports and intervention studies of nosocomial infection statement using a comprehensive checklist and summary table to improve the quality of describing these reports and studies transparently. ${ }^{25}$ Reporting outbreaks in a well-organized and transparent manner and sharing lessons learned from outbreak investigations is essential because designing a high quality of outbreak investigations, including randomized controlled trials, is difficult or impossible (ie, most outbreaks were reported by case reports and authors' interest). It is also necessary to devise practical epidemiologic indicators for evaluating an actual status of health care-associated outbreaks that may not have been published in most cases. In our facility, only a few outbreaks which occurred during the study period have been published so far. ${ }^{9,14}$ Another limitation is that few investigations determined reservoirs, sources, and transmission routes because most outbreaks were addressed before environmental or hand sampling was implemented and infection control measures were prioritized as a practice.

In conclusion, this study demonstrated significant differences in epidemiologic characteristics of multiple health care-associated outbreaks between ICUs and non-ICUs. Our analysis also provided insight into the usefulness of routine molecular analysis in assessing the transmission of MDROs and understanding the epidemiology of outbreaks. These findings are important to implement appropriate infection prevention strategies against health care-associated outbreaks and avoid prolonged transmission. Further pragmatic approaches and research to improve comparability in descriptions of outbreaks (eg, developing meaningful definition of a health careassociated outbreak, establishing comparable epidemiologic indicators of intra- and intertransmission of pathogens causing an HAI) will be needed.

\section{References}

1. Weber DJ, Anderson D, Rutala WA. The role of the surface environment in healthcare-associated infections. Curr Opin Infect Dis 2013;26:33844.

2. Kanamori H, Rutala WA, Sickbert-Bennett EE, Weber DJ. Review of fungal outbreaks and infection prevention in healthcare settings during construction and renovation. Clin Infect Dis 2015;61:433-44.

3. Kanamori H, Weber DJ, Rutala WA. Healthcare outbreaks associated with a water reservoir and infection prevention strategies. Clin Infect Dis 2016;62:142335.

4. Sood G, Perl TM. Outbreaks in health care settings. Infect Dis Clin North Am 2016;30:661-87.
5. Danzmann L, Gastmeier P, Schwab F, Vonberg RP. Health care workers causing large nosocomial outbreaks: a systematic review. BMC Infect Dis 2013;13:98.

6. Vonberg RP, Weitzel-Kage D, Behnke M, Gastmeier P. Worldwide Outbreak Database: the largest collection of nosocomial outbreaks. Infection 2011;39:2934.

7. Gastmeier P, Vonberg RP. Outbreaks of nosocomial infections: lessons learned and perspectives. Curr Opin Infect Dis 2008;21:357-61.

8. Centers for Disease Control and Prevention, National Healthcare Safety Network. Surveillance definition of healthcare-associated infection and criteria for specific types of infections in the acute care setting. Available from: http://www.cdc.gov/nhsn/PDFs/pscManual/17pscNosInfDef_current.pdf. Accessed April 18, 2017.

9. Teal LJ, Schultz KM, Weber DJ, Gergen MF, Miller MB, DiBiase LM, et al. Invasive cutaneous Rhizopus infections in an immunocompromised patient population associated with hospital laundry carts. Infect Control Hosp Epidemiol 2016;37:1251-3

10. Kanamori H, Weber DJ, DiBiase LM, Sickbert-Bennett EE, Brooks R, Teal L, et al. Longitudinal trends in all healthcare-associated infections through comprehensive hospital-wide surveillance and infection control measures over the past 12 years: substantial burden of healthcare-associated infections outside of intensive care units and "other" types of infection. Infect Control Hosp Epidemiol 2015;36:1139-47.

11. Gastmeier P, Loui A, Stamm-Balderjahn S, Hansen S, Zuschneid I, Sohr D, et al. Outbreaks in neonatal intensive care units-they are not like others. Am J Infect Control 2007;35:172-6.

12. Branski LK, Al-Mousawi A, Rivero H, Jeschke MG, Sanford AP, Herndon DN. Emerging infections in burns. Surg Infect (Larchmt) 2009;10:389-97.

13. Kanamori H, Parobek CM, Weber DJ, van Duin D, Rutala WA, Cairns BA, et al. Next-generation sequencing and comparative analysis of sequential outbreaks caused by multidrug-resistant Acinetobacter baumannii at a large academic burn center. Antimicrob Agents Chemother 2015;60:1249-57.

14. Kanamori H, Parobek CM, Juliano JJ, van Duin D, Cairns BA, Weber DJ, et al. A prolonged outbreak of KPC-3-producing Enterobacter cloacae and Klebsiella pneumoniae driven by multiple mechanisms of resistance transmission at a large academic burn center. Antimicrob Agents Chemother 2017;61.

15. Kambhampati A, Koopmans M, Lopman BA. Burden of norovirus in healthcare facilities and strategies for outbreak control. J Hosp Infect 2015;89:296-301.

16. Weber DJ, Sickbert-Bennett EE, Vinje J, Brown VM, MacFarquhar JK, Engel JP, et al. Lessons learned from a norovirus outbreak in a locked pediatric inpatient psychiatric unit. Infect Control Hosp Epidemiol 2005;26:841-3.

17. Luo R, Greenberg A, Stone CD. Outcomes of Clostridium difficile infection in hospitalized leukemia patients: a nationwide analysis. Infect Control Hosp Epidemiol 2015;36:794-801.

18. Eyre DW, Cule ML, Wilson DJ, Griffiths D, Vaughan A, O'Connor L, et al. Diverse sources of $\mathrm{C}$. difficile infection identified on whole-genome sequencing. $\mathrm{N}$ Engl J Med 2013;369:1195-205.

19. Salipante SJ, SenGupta DJ, Cummings LA, Land TA, Hoogestraat DR, Cookson BT. Application of whole-genome sequencing for bacterial strain typing in molecular epidemiology. J Clin Microbiol 2015;53:1072-9.

20. Pinholt M, Larner-Svensson H, Littauer P, Moser CE, Pedersen M, Lemming LE, et al. Multiple hospital outbreaks of vanA Enterococcus faecium in Denmark, 2012-13, investigated by WGS, MLST and PFGE. J Antimicrob Chemother 2015;70:2474-82.

21. Centers for Disease Control and Prevention. Guidelines for environmental infection control in health-care facilities: recommendations of CDC and the Healthcare Infection Control Practices Advisory Committee (HICPAC). MMWR Recomm Rep 2003;52:1-48.

22. Hansen S, Stamm-Balderjahn S, Zuschneid I, Behnke M, Rüden H, Vonberg RP, et al. Closure of medical departments during nosocomial outbreaks: data from a systematic analysis of the literature. J Hosp Infect 2007;65:348-53.

23. Weber DJ, Kanamori H, Rutala WA. "No touch" technologies for environmental decontamination: focus on ultraviolet devices and hydrogen peroxide systems. Curr Opin Infect Dis 2016;29:424-31.

24. Anderson DJ, Chen LF, Weber DJ, Moehring RW, Lewis SS, Triplett PF, et al Enhanced terminal room disinfection and acquisition and infection caused by multidrug-resistant organisms and Clostridium difficile (the Benefits of Enhanced Terminal Room Disinfection study): a cluster-randomised, multicentre, crossover study. Lancet 2017;389:805-14.

25. Stone SP, Cooper BS, Kibbler CC, Cookson BD, Roberts JA, Medley GF, et al. The ORION statement: guidelines for transparent reporting of outbreak reports and intervention studies of nosocomial infection. Lancet Infect Dis 2007;7:282-8. 